\title{
Presuppositions as Beliefs
}

\author{
Diane HORTON and Graeme HIRST \\ Department of Computer Science \\ University of Toronto \\ Toronto, Canada M5S 1A4 \\ dianeh@ai.toronto.edu (CSNET)
}

\begin{abstract}
Most theorits of presupposition implicitly assume that presuppositions: are facts, and that all agents involved in a discourse share belief in the presuppositions that it generates. These unrealistic assumptions can be eliminated if each presupposition is treated as the belief of an agent. However, it is not enough to consider only the beliefs of the speaker; we show that the beliefs of other agents are often involved. We describe a new model, including an improved definition of presupposition, that treats presuppositions as beliefs and considers the beliefs of all agents involved in the discourse. We show that treating presuppositions as beliefs makes it possible to explain phenomena that cannot be cxplained otherwise.
\end{abstract}

\section{Introduction}

In addition to its literal meaning, a sentence or utterance conveys a host of indirect information that can be pragmatically inverred. Presuppositions, which we mark "》", are one part of that information. Table 1 gives several examples of presupposition with their traditional analyses ${ }^{1}$.

Roughly, a presupposition is a proposition that is conveyed by a sentence or utterance ${ }^{2}$ but is not part of the main point, and must be consistent with the established context in order for that sentence or utterance to be felicitous. For example, the following is infelicitous because the second sentence presupposes that Angie quit, which contradicts the first sentence:

(1) *Angie didn't quit. It's surprising that she quit.

Other types of pragmatic inference include entailment, conversational implicature, and conventional implicature (see Levinson (1983) for detailed descriptions). Presuppositions can be distinguished from other sorts of pragmatic inference by their unique behavior when the sentence from which they originate is negated. These basic ideas are generally agreed upon; however, their formalization into a theory of presupposition has been difficult. We will now introduce two problems and our approach to solving them.

\footnotetext{
1 Throughout this paper, we use the sentence itself as short form for its semantic representation, in order to avoid addressing the orthogonal issue of semantic representation.

${ }^{2}$ The sentence/utterance distinction will be nade clear in the presentation of our approach.
}

Horton (1987) reviews several thcories, including those of Karttunen $(1973,1974)$, Karttunen and Peters (1979), Wcischedel (1975, 1979), Gazdar (1979a, 1979b), Wilson and Sperber (1979), and Atlas and Levinson (1981). One problem is that many thcories of presupposition implicitly make the following unrenlistic assumptions ${ }^{3}$ :

- Truth Assumption: If sentence $S$ (or its utterance) presupposes proposition $P$, then $P$ is true.

- Shared Belief Assumption: If sentence $S$ (or its uttterance) presupposes proposition $P$, then all agents involved share the prior belief that $P$ is true.

Weischedel and Gazdar are exceptions; each of them attributes presuppositions to the spcaker as either knowl. edge or belief. However, we will show that the beliefs of agents other than the speaker must be considered in order to correctly express many presuppositions. Our approach is to treat presuppositions as beliefs, but also to consicler the beliefs of all agents involved in discourse.

A second difficulty has been in finding an adequate definition of presupposition. Many definitions state that the presuppositions of a sentence must be known prior to the utterance of that sentence to avoid infelicity. Some have the stronger constraint that the presuppositions must be mutually known by all participants. The following definition (Levinson 1983, 205) has these properties:

DEFINITION 1: An utterance $A$ pragmatically presupposes a proposition $B$ iff $A$ is appropriate only if $B$ is mutually known by participants.

These requirements, which reflect the Shared Belief Assumption, are too strict - presuppositions are often used to introduce new information. Conversely, many definitions accept inferences from the other inference classes as presuppositions. Our definition, to be presented in section 3.2 , weakens the overly strict prior knowledge condition so that it does not reject valid presuppositions, and avoids accepting inferences from other classes by checling whether each candidate exhibits the clistinctive behavior under negation that signifies a presupposition. Hence, the new definition captures presupposition more preciscly.

The next section describes the unique behavior of presuppositions under negation. In section 3 the cletails of our

\footnotetext{
${ }^{3}$ Here both sentences and utterances are mentioned bectuse tho assumptions are generally made when either is analyzed.
} 


\begin{tabular}{||l|l||}
\hline \multicolumn{1}{|c|}{ Trigger } & \multicolumn{1}{|c||}{ Example } \\
\hline \hline Factive verb & $\begin{array}{l}\text { Rita is upget that Jenny lied. } \\
\text { \enny lied. }\end{array}$ \\
\hline It-cleft & $\begin{array}{l}\text { It was Pauline who told Arthur about Michelle. } \\
\text { Someone told Arthur about Michelle. }\end{array}$ \\
\hline Change-of-state verb & $\begin{array}{l}\text { Tom finished making dinner. } \\
\text { Tom had been making dinner. }\end{array}$ \\
\hline Non-restrictive relative clause & $\begin{array}{l}\text { Kerry, who is Jay's son, was married last month. } \\
\text { MKerry is Jay's son. }\end{array}$ \\
\hline Implicative verb & $\begin{array}{l}\text { Mom forgot to call. } \\
\text { Mom intended to call. }\end{array}$ \\
\hline Definite description & $\begin{array}{l}\text { The person who stole Dr. Legg's file used a key. } \\
\text { There is a person who stole Dr. Legg's file. }\end{array}$ \\
\hline Verb of judging & $\begin{array}{l}\text { I congratulated Lois when she finished her thesis. } \\
\text { For Lois to finish her thesis was a good thing. }\end{array}$ \\
\hline
\end{tabular}

Table 1: Some common triggers of presupposition, with examples.

approach are presented. We then compare our analysis with that of Gazdar, and conclude with a summary.

\section{Behavior under Negation}

It is often stated that presuppositions are constant under negation, as in example 2, but are also defeasible. By this view, the presupposition in example 3 remains constant under the negation in the first sentence, but is later defeated by the second sentence.

(2) Calvin $\{$ did $\mid$ didn't $\}$ stop going to college.

$\gg$ Calvin had been going to college.

(3) I don't wish I had a Porsche - I already have one. $\$$ I don't have a Porsche.

Our explanation of this behavior is different. Before presenting it, some terminology must be introduced.

We will make the following semantic distinction between two kinds of negation. Internal negation has a particular element of its scope as its focus, in the sense of the terms defined by Quirk and Greenbaum (1973, 187188). External negation focuses on an unspecified component of its scope and therefore has several possible interpretations. The following sentence contains external negation. It has at least three interpretations:

(4) The boogieman didn't blow the door shut.

(a) It's still open.

[negating the main proposition]

(b) There is no boogieman.

[ negating a presupposition]

(c) It was already shut.

[ negating a felicity condition ]

The focus of internal negation is unambiguous. If that focus is on a presupposition, the presupposition, of course, does not survive the negation, as in the following:

(5) Mark, who has a Ph.D., is the president. $\gg$ Mark has a Ph.D.
(6) Mark, who doesn't have a Ph.D., is the president. $\$$ Mark has a Ph.D.

Internal negation that focuses on anything other than a presupposition does not affect that presupposition, because presuppositions do not depend on the truth of any other thing expressed by the sentence. For exarnple, the presupposition of sentence 7 still holds when the main proposition is negated.

(7) Debbie, who has a dog, \{does $\mid$ doesn't $\}$ have cats.

$\gg$ Debbie has a dog.

External negation is inherently vague. We argue that it is handled as follows. One first checks to see if there is any evidence favoring one of the possible interpretations. If a presupposition contradicts any established information, one assumes the intended reading negates that presupposition; hence the presupposition is never believed to hold. We will call this the blocking of a presupposition. In the absence of any evidence to guide one in choosing an interpretation, one assumes that negation of the main proposition was intended, and hence that the presupposition stands. This assumption might be either supported or refuted by information to follow. If it is refuted, then the incorrect presupposition must be retracted.

Our analysis of example 3 then, is as follows. The negation in the first sentence is ambiguous and, on hearing that sentence alone, the hearer assumes a reading where the focus of negation is on wish and the presupposition is left intact. That is, the hearer assumes the intended reading was I don't have a Porsche, and I don't want one. On hearing the second sentence, the hearer learns that this assumption was incorrect, and the presupposition that $I$ don't have a Porsche is retracted.

In summary, a presupposition survives semantically internal negation exactly when the negation does not focus on the presupposition itself. It is assumed to survive semantically external negation unless there is evidence to the contrary, in which case it is blocked. If not blocked, it 
may be reiracted later if the assumption is shown to be incorrect by evidence that follows. We use the term defeat to subsume both blocking and retraction. Horton (1987, sec. 1.2) shows that this behavion distinguishes presuppositions from entailments and implicatures.

\section{Presuppositions as Beliefs}

The approach proposed here is to treat each presupposition as the belief of some particular agent in order to avoid the assumptions of truth and shared belief and thercby attain a more realistic account of presupposition. In addition, we propose considering all agents when cleciding to whom the belief should be attributed.

Before continuing, we will point out our assumptions. Following Grice (1975), we assume first that no speaker will delibecately try to deceive the listener, and second that no speaker will use irony or sarcasm. Deccit, irony, and sarcasm can affect presuppositions, and the possibility of handling them is discussed by florton (1987).

\subsection{A Logic for Modeling Context}

In (Horton 1987) a formal logic of belief is defined. Its syntax allows the expression of propositions such as $B_{J_{o h n}} B_{M a n y^{-}} P$ (that is, John believes that Mary believes $P$ is not true). Its semantics is based on belief structures, a variant of Fagin, Halpern, and Vardi's knowledge structures (1984). A belief structure encodes what will be called a state - the truth valuc of cach proposition, as well as the beliefs of each agent regarding these propositions, their beliefs about the other agents' beliefs, and so on. If a proposition $P$ is true for a beliof structure $s$, we write $s \models P$; if not, we write $s \not \models P$. We also informally describe operations $A d d$ Proposition, which updates a belief structure to encode a new belief for some agent, and Retract Proposition, which retracts a proposition from an agent's beliefs. These operations can be used to model the acquisition and retraction of presuppositional information by agents. Formal definitions of these operations raise difficult problems that wo have not solved. See (Horton 1987?, 37-42). However, the logic does provide a notation and formal semantics for the expression of beliefs.

\subsection{The Definition of Presupposition}

We now present a definition of presupposition that embodies the idea of attributing presuppositions to specific agents, and incorporates our view of the behavior of presuppositions: under negation.

The puesuppositions of an utterance depend not only on the sentence uttered, but also on the speaker, the listener, and the listener's beliefs, since only the listener's beliefs affect the cancellation of presuppositions for him. One sometimes wishes to speak of presuppositions when not all of this contextual information is known. In particular, it is dessirable to be able to discuss presuppositions of a sentence independent of any context of utterance. In such cases, it is not possible to perform a consistency check to determine whether or not a candidate will actually turn out to be a presupposition; but one can say that if the necessary information were available and if the proposition were consistent with established information, then the proposition would be a presupposition. We will define potential presupposition to capture this notion of a candidate presupposition that may turn out to hold when the sentence is completely situated, and actual presupposition to denote a potential presupposition that does turn out to hold ${ }^{4}$.

In the definitions below, $S^{+}$is used to represent the affirmative form of sentence $S$, and $S^{-}$to represent the cxternally negated form of the sentence. We will use the term state to refer to a statc of affairs, as represented by a belief structure.

\section{Potential Presupposition}

The definition of potential presupposition for when only the sentence is known is as follows:

DErinition 2: Sentence $S$ potentially presupposes proposition $P$ iff for any speaker $S p$, listencr $L$, and state $s$,

(a) The utterance of $S^{+}$by $S p$ to $L$ in state $s$ would allow $L$ to infer $B_{S y} P$.

(b) The utterance of $S^{-}$by $S p$ to $L$ in state $s$ would allow $L$ to infer $B_{S_{p}} P$ unless $L$ already believed $B_{S p} \neg P$, i.e, unless $s \models B_{L} B_{S_{p}} \neg P$.

Clause (a) says that if the affirmative form of the sentence were spoken, any listener could infer that the speaker believed $P$. Clause (b) says that even if the negative form of the sentence were spoken, any listener could still infer that the speaker believed $P$, unless the listencr alrearly believed otherwise. A definition with clause (a) alone would capture other pragmatic inferences as well as presupposition. Since clause (b) requires that the cancliclate exhibit the behavior under negation that is unique to presupposition, it excludes the others. See (Horton 1987, sec. 4.5) for examples.

\section{Actual Presupposition}

An actual presupposition of a sentence completely situated in context must be a potential presupposition of that sentence and consistent with the context.

DEFINITION 3: The utterance of sentence $S$ by speaker $S p$ in statc $s$ actually presupposes proposition $B_{S p} P$ for listener $L$ iff

(a) $P$ is a potential presupposition of $S$.

(b) If $S=S^{-}, s \not \forall B_{L} B_{S_{p} \rightarrow P}$.

In keeping with our philosophy of treating presuppositions as beliefs, clause (b) checks whether the speaker believes the potential presupposition according to the listener. Since blocking can only occur in negative sentences,

\footnotetext{
${ }^{4}$ See section 4 for a comparison of our concepts of potential and actual presupposition with Gaydar's "pre-supposition" and "actual presupposition."
} 
this check is only performed on negative sentences (see section 3.4 for a qualification).

\section{Example}

Consider the utterance of $S=I$ 'm not glad that Chris is leaving by Tom. Let $P$ be Chris is leaving, and the statc be $s$ where $s \notin B_{\text {Diane }} B_{\text {Tom }} P, s \notin B_{\text {Diane }} B_{\text {Tom }} \neg P$, and $\left.s=B_{\text {Cathie }} B_{\text {Tom }}\right\urcorner P$. The sentence is already externally negated, so $S^{-}=S$, and $S^{+}=I t$ is not true that $I^{\prime} m$ not glad that Chris is leaving, which is equivalent to I'm glad that Chris is leaving.

For any speaker $S p$, listener $L$, and state $s$, the utterance of $S^{+}$by $S p$ would allow $L$ to conclude $B_{S p} P$. We can confirm this by noting that the utterance of I'm glad that Chris is leaving, but he isn't would be infelicitous. In addition, the utterance of $S^{-}$by any speaker $S p$ would also allow any listener $L$ to conclude $B_{S p} P$, unless it were inconsistent with $L$ 's beliefs. Therefore, $P$ is a potential presupposition of sentence $S$.

$P$ may or may not be an actual presupposition of the utterance of $S$ by Tom in this state, depending on who is the listener. Diane has no particular belief about whether or not Tom thinks Chris is leaving. In particular, $s \not \neq B_{\text {Diane }} B_{\text {Tom }} \neg P$. Therefore, $B_{\text {Tom }} P$ is an actual presupposition to Diane of the utterance of sentence $S$ by Tom, in this state. However, Cathie has the previous belief that Tom thinks Chris is not leaving, i.e., $s \models B_{\text {Cathie }} B_{\text {Tom }} \neg P$. Therefore, $B_{\text {Tom }} P$ is not an actual presupposition to Cathie of the utterance of sentence $S$ by Tom, in this state.

\subsection{Applying the Definitions}

Horton (1987, ch. 5) applies the definitions, in the manner shown above, to a representative set of simple sentences, and shows that the presuppositions of many sentences must be treated as beliefs. For example, sentence 8 does not potentially presuppose Brian's leaving was bad, as shown by the felicity of 9 . However, under our assumption that all speakers are sincere, it does potentially presuppose $B_{\text {Percy }}$ (Brian's leaving was bad).

(8) Percy criticized Brian for leaving.

(9) Percy criticized Brian for leaving, but there was nothing wrong with him leaving.

In the case of utterances, all presuppositions must be treated as the beliefs of the speaker, but many can be correctly expressed only if the beliefs of agents other than the speaker can also be mentioned. For example, consider the following utterance of 8 :

(10) Mavis: Percy criticized Brian for leaving.

Brian's leaving was bad.

$\ngtr B_{\text {Mavis (Brian's leaving was bad) }}$

$\gg B_{\text {Mavis }} B_{\text {Percy }}$ (Brian's leaving was bad)

Because our approach models the beliefs of all agents, it is capable of correctly handling these cases.

For complex sentences, one can either again apply the definitions directly or attempt to find rules for determining the potential presuppositions of the sentence from those of its constituents. Horton (1987, chapter 6) examines this projection problem and shows that beliefs are again important. For example, when sentence 11 is embedded in the context of the verb hopes, another level of belief is necessary to express the potential presupposition correctly.

(11) Lofty is sorry that he upset Willie. $\gg B_{\text {Lofty }}$ (Lofty upset Willie).

(12) Ethel hopes Lofty is sorry that he upset Willie. $\gg B_{E t h e l} B_{\text {Lofty }}$ (Lofty upset Willie).

The felicity of sentence 13 below shows that 12 does not simply carry the potential presupposition, $B_{\text {Lofty }}$ (Lofty upset Willie), of its constituent 11.

(13) Ethel hopes Lofty is sorry that he upset Willie. She doesn't realize that Lofty doesn't even know he did.

Any account that does not treat presuppositions as beliefs cannot capture the presupposition in 12 and must incorrectly consider verbs of propositional attitude such as hopes (as well as verbs of saying) to block this projection. Even an account that treats presuppositions as beliefs, but considers only the beliefs of the speaker, cannot capture this presupposition.

The initial motivation for treating presuppositions as beliefs was to avoid two unrealistic assumptions. We have now seen that some cases of projection cannot be handled otherwise, and that many presuppositions do involve beliefs of agents other than just the speaker.

\subsection{Defeat in Affirmative Sentences}

The presuppositions of an affirmative sentence usually cannot be defeated without an infelicity. For example, It's a good thing that Tom didn't fall presupposes that Tom didn't fall. There is no context for this sentence in which the presupposition does not hold and hence no context in which it can be contradicted. However, there is a small class of affirmative sentences in which defeat is possible. For example, sentence 14 potentially presupposes 15 because of the definite reference Barney's loud music.

(14) If Fred's in his office, Barney's loud music will bother him.

(15) Barney is playing loud music.

However, in the context of 16 , the presupposition does not hold.

(16) Barney plays loud music when Fred's in his office, just to bother him.

In this case, the contextual information combines with the if-clause of 14 to establish that the potential presupposition of the then-clause, 15 , is merely a possibility, thereby blocking it as an actual presupposition of the sentence. We argue that a presupposition of an affirmative sentence can be defeated only in this manner, i.e., only if it is established as hypothetical by a clause of the sentence in combination with contextual information. Horton (1987) enumerates these relatively infrequent cases. 
Definitions 2 and 3 , given above, correctly handle the cases in which attempted defeat of a presupposition arising from an affirmative sentence leads to an infelicity; however, they do not handle those cases where such defeat is possible. In this section we discuss two ways to do so. Both are compacible with our approach.

We define an anti-condition to be any background information that helps to establish as hypothetical, and therefore to defeat, a potential presupposition of an affirmative sentence. Clauses involving anti-conclitions are added to the definitions as follows:

DEFINITION 4: Sentence $S$ potentially presupposes proposition $P$ with anti-condition $Q$ iff for any spealer $S p$, listencr $L$, and state $s$,

(a) The utterance of $S^{+}$by $S p$ to $L$ in state $s$ would allow $L$ to infer $B_{S p} P$ unless $L$ already believed $B_{S p} Q$, i.e., unless $s \mid=B_{L} B_{S p} Q$.

(b) The utterance of $S^{-}$by $S p$ to $L$ in state $s$ would allow $L$ to infer $B_{S p} P$ unless $L$ alrcady believed $B_{S p} \neg P$ or $B_{S p} Q$, i.e., unless $\&=B_{L} B_{S_{p}} \neg P$ or $s=B_{L} B_{S p} Q$.

Definimion 5: The utterance of sentence $S$ by speaker $S p$ in state $s$ actually presupposes proposition $B_{S p} P$ for listener $L$ iff

(a) $P$ is a potential presupposition of $S$, with anticondition $Q$.

(b) If $S=S^{-}, s \not \forall B_{L} B_{S_{p}} \neg P$.

(c) $s \nLeftarrow B_{L} B_{S_{p}} Q$.

For example, sentence 14 potentially presupposes 15 with 16 as an anti-condition. As long as the anti-condition is not believed, the presupposition is actual.

As mentioned above, defeat can only occur in a few types of positive sentence, so the anti-condition is usually nil; in such cases the simpler definitions, 2 and 3 , suffice.

An alternative method of handling the phenomena regarding defeat in affirmative sentences is to treat affirmative and negative sentences uniformly, that is, to perform the consistency check on both types of sentence. This approach, adopted by Gazdar (1979a, 1979b), xequires no special mechanism to account for felicitous defeat in affirmative sentences. To cxplain the infelicity that arises in most cases when defeat of a presupposition of an affirmative sentience is attempted, the help of entailments is enlisted. For example, Gazdar's theory says that I didn't see Les Misérables is a "pre-supposition"s of 18, but not an actual presupposition in the context of 17 , because this would be inconsistent. So far no infelicity is detected.

(17) I saw Les Misérables.

(18) I'm sorry that I didn't sec it.

However, I didn't see Les Misérables is also an entailment, of 18 (bectuse factive verbs cntail their complements).

\footnotetext{
${ }^{5}$ Gazdar's "pre-suppositions" correspond roughly to our potential presuppositions (sce section 4 ). We will use quotation marks to distinguish his hyphenated term from the generic one.
}

This entailment introduces an inconsistency into the cumulative context and sentence 18 is therefore predicted to be infelicitous in the context of 17 .

Unfortunately, Gazdar does not say exactly where such entailments occur. We argue that the entailments exist exactly where anti-conditions do not, and thiss that the distinction between affirmative sentences that allow defeat and those that do not can be drawn either by anticonditions or by the existence of entailments.

Casting the "uniform" approach in our torms, we get the following definitions:

Definition 6: Sentence $S$ potentially presupposes proposition $P$ iff for any speaker $S p$, listencr $L$, and state $s$, the utterance of $S$ by $S p$ to $L$ in state $s$ would allow $L$ to infer $B_{S p} P$ unless $s \neq B_{L} B_{S p}-P$.

Difinition 7: The utterance of sentence $S$ by speaker $S_{p}$ in state $s$ actually presupposes proposition $B_{S p} P$ for listener $L$ iff

(a) $P$ is a potential presupposition of $S$.

(b) $s \forall B_{L} B_{S_{p}} \neg P$.

We are at present undecided as to which of these two methods to prefer. Both explain the phenomona. Treating affirmative and negative sentences uniformly leads to simpler definitions; in addition, the use of entailments to explain defeat phenomena in positive sentences is more general than relying on anti-conditions, which are specific to the type of sentence under question. However, this approach does not capture the intuition that defeat differ's in negative and affirmative sentences. In addition, uniform definitions do not capture only presupposition, because they do not mention the unique behavior of presupposi. tion under negation. In contrast, the earlier definitions 4 and 5 can distinguish presupposition from other kinds of implication.

It is important to note that the choice between these two methods is orthogonal to our goal of developing a model that treats presuppositions as beliefs.

\section{Comparison with Gazdar's Approach}

Gazdar's (1979a, 1979b) is perhaps the nnost influential theory of presupposition. It attempts to explain diverse phenomena regarding the behavior of presuppositions in context ${ }^{6}$ with a single rule, based on consistency. Consistency is also central to our analysis. In addition, the structure of our account is similar to Gazdar's. In particular, both accounts first compute preliminary propositions - in our case potential presuppositions and in Gazdar's, "pre-suppositions" - and then perform a consistencybased context clieck to find the presuppositions of the sen-

\footnotetext{
${ }^{6}$ Gazdar refers to this as the projection problen. We use the term differently, as Levinson does, to mean the problem of finding the presuppositions of a complex sentence from the presuppositions of its constituents.
} 
tence or utterance in context. Despite the structural similarities, there are important differences between the two approaches. We will now describe some of these.

First, for Gazdar a sentence may "pre-suppose" a proposition that it can never, on any occasion of use, presuppose. His "pre-suppositions" are simply convenient intermediate results. In our theory, on the contrary, to say that a sentence $S$ potentially presupposes proposition $P$ is to make a general statement about sentence $S$ : it tends to imply $P$. Second, Gazdar computes his "pre-suppositions" using a set of unconnected and unmotivated rules, whereas our definition of potential presupposition lends coherence to the diverse class of potential presuppositions. The key difference between the present work and Gazdar's is that our emphasis is not on the behavior of presuppositions in context, but on the relevance of agents' beliefs to all aspects of presupposition. Gazdar does not address this issue. $^{7}$ We consider our integration of beliefs into an account of presupposition to be our main contribution.

\section{Summary}

We have found that agents' beliefs are relevant to an account of presupposition, and that it is necessary to consider all agents involved in discourse when deciding to whom belief in a presupposition should be attributed. We have described an account of presupposition that therefore makes beliefs central. This account includes a new definition of presupposition that captures it more precisely than earlier ones.

Treating presuppositions as beliefs - with full consideration given to all agents' beliefs - not only allows a more correct analysis by avoiding the Truth Assumption and the Shared Belief Assumption; it also makes it possible to account for presuppositional phenomena that could not be explained otherwise.

\section{Acknowledgements}

This paper is based on thesis work by the first author, under the supervision of the second. The authors wish to thank Brenda Fawcett, Gerhard Lakemeyer, Hector Levesque, and Bart Selman for helpful discussions, and Chrysanne DiMarco and Susan McRoy for help in preparing this paper. Financial support was received from the Natural Sciences and Engineering Research Council of Canada.

\section{References}

Atlas, J.D.; and Levinson, S.C. 1981. It-Clefts, Informativeness, and Logical Form: Radical Pragmatics (Revised Standard Version). In Cole, P. Ed., Radical Pragmatics. Academic Press: 1-61.

Fagin, Ronald; Halpern, Joseph Y.; and Vardi, Moshe Y. 1984. A Model-Theoretic Analysis of Knowledge: Preliminary Report. Proceedings of the 25th IEEE Symposium on Foundations of Computer Science. West Palm Beach, Florida: 268-278.

Gazdar, G. 1979a. Pragmatics: Implicature, Presupposition and Logical Form. Academic Press.

Gazdar, G. 1979b. A Solution to the Projection Problem. In $\mathrm{Oh}$ and Dinneen 1979: 57-89.

Grice, H. Paul. 1975. Logic and Conversation. In Cole, Peter J.; and Morgan, Jerry L., Eds. Syntax and Semantics, Volume 3: Speech Acts. Academic Press: 41-58.

Horton, Diane Lynn. 1987. Incorporating Agents' Beliefs in a Model of Presupposition. M.Sc. thesis, published as Technical Report CSRI-201, Computer Systems Research Institute, University of Toronto, Toronto, Canada.

Karttunen, Lauri. 1973. Presuppositions of compound sentences. Linguistic Inquiry 4:169-193.

Karttunen, Lauri. 1974. Presupposition and linguistic context. Theoretical Linguistics 1:181-194.

Karttunen, Lauri; and Peters, Stanley. 1979. Conversational Implicature. In $\mathrm{Oh}$ and Dinneen 1979: 1-56.

Levinson, S.C. 1983. Pragmatics. Cambridge University Press.

Oh, C.-K.; and Dinneen, D.A., Eds. 1979. Syntax and Semantics, Volume 11: Presupposition. Academic Press.

Quirk, Randolph; and Greenbaum, Sidney. 1973. A University Grammar of Engligh. Longman Group Limited.

Weischedel, Ralph Mark. 1975. Computation of a Unique Subclass of Inferences: Presupposition and Entailment. Unpublished doctoral dissertation, University of Pennsylvania.

Weischedel, Ralph Mark. 1979. A New Semantic Computation While Parsing: Presupposition and Entailment. In $\mathrm{Oh}$ and Dinneen 1979: 155-183.

Wilson, Dierdre; and Sperber, Dan. 1979. Ordered Entailments: An Alternative to Presuppositional Theories. In $\mathrm{Oh}$ and Dinneen 1979: 299-323.

\footnotetext{
${ }^{7}$ As mentioned above, Gazdar does treat all presuppositions as knowledge of the speaker; however, he does not consider the knowledge or beliefs of other agents, or examine the relevance of beliefs or knowledge to a theory of presupposition.
} 